\title{
L'èxtasi poètic de Fontanella: metateatre i música a la Lloa per la Tragicomèdia pastoral d'amor, firmesa i porfia
}

\author{
The poetic estasy of Fontanella: metatheatre and music in Lloa per la \\ Tragicomèdia pastoral d'amor, firmesa i porfia
}

GASTON GILABERT gastongilabert@gmail.com

Universitat de Barcelona

Resum: En absència d'estudis monogràfics sobre la Lloa de Fontanella, aquest article n' analitza l'estructura dramàtica, començant amb una reflexió sobre llur classificació dintre del gènere i sobre l'espai de la Barcelona del segle XVII que podria haver-la escenificat. La importància funcional que el poeta barceloní atorga a la música i al metateatre condueixen a una interpretació de la Lloa des d'un punt de vista poeticomusical, la qual cosa permet una nova lectura de certs passatges $i$ una valoració crítica que afecta, no només a la peça en qüestió sinó a tota la Tragicomèdia pastoral d'amor, firmesa i porfia i al caràcter d'avantguarda del teatre català de l'Edat Moderna

Paraules clau: Francesc Fontanella, teatre català, literatura barroca, música, Barcelona.

Abstract: In the absence of monographic studies on Fontanella's Lloa, this paper analyses its dramatic structure, starting with a reflection on their classification within the genre and on the context of 17 th century Barcelona where it could have been staged. The functional importance that this Barcelonian poet grants to music and metatheatre leads to an interpretation of the Lloa from a poetic-musical point of view, which allows a new reading of certain passages and a critical evaluation that affects not only the piece in question, but also the whole Tragicomeddia pastoral d'amor, firmesa i porfia and the avant-garde character of the Catalan theatre of the Modern Age.

Keywords: Francesc Fontanella, Catalan theatre, baroque literature, music, Barcelona. 
Gaston Gilabert. L’èxtasi poètic de Fontanella: metateatre i música a la Lloa per la Tragicomèdia pastoral d'amor, firmesa i porfia

\section{Introducció ${ }^{1}$}

Després del gran període de crisi sistèmica del Renaixement en què les antigues autoritats havien quedat contradites i ja ningú no podia mirar el firmament amb la certesa d'abans, ni assegurar que la seva espècie era el centre de l'univers, el Barroc rep un llegat caracteritzat per la problematització de la mirada. Amb l'ús del clarobscur i el trompe-l'œil, l'estètica barroca desdibuixa sovint les línies de la perspectiva, interposa miralls entre el subjecte i l'objecte de la percepció i duu l'espectacularitat teatral fora dels escenaris. En conseqüència, el personatge dramàtic ja no se sent l'únic habitant d'un món artificial, ja que tot el que pot percebre l'ésser humà és fruit de sentits i discursos fal libles per naturalesa. És lògic, doncs, que la pregunta sobre si la realitat és somni o il lusió esdevingui un tòpic i que els actors trenquin definitivament les fronteres de la ficció amb l'objectiu de qüestionarse, no només les regles del joc teatral, sinó també i sobre tot les del teatre del món. No és casual que personatges tan universals com Hamlet, Don Quixot, Otel lo o el Segismundo de La vida es sueño estiguin travessats per la pregunta sobre la realitat, l'aparença i el fingiment.

En aquest estat de coses en què la vida ha quedat contaminada per l'estatut ficcional, el lector i l'espectador barrocs fàcilment poden caure en el parany del perceptor percebut, un dels recursos més habituals de l'art de l'Edat Moderna, que situa la humanitat en un laberint de paraules on els sentits, més que certeses, projecten preguntes. La subjectivitat errant que havia estat disseccionada fins a límits mai vistos en l'obra de Montaigne esdevé una trampa i un joc d'il lusions en la de Velázquez.

Dins de la tradició literària catalana d'època moderna, Francesc Fontanella és el dramaturg més conscient d'aquests artificis metaliteraris i ho demostra amb un teatre autoreferencial capaç de dialogar amb els grans autors europeus del segle XVII. En aquest treball hem seleccionat la Lloa per la Tragicomèdia pastoral d'amor, firmesa i porfia, per ser el pòrtic d'una festa teatral barroca i per ser, com a tal, la peça que prepara l'espectador amb una espessor de signes poeticomusicals i jocs de miralls que la converteixen en un veritable monument literari de l'Edat Moderna.

Ha estat molt escassa l'atenció crítica que ha rebut aquesta peça, fins i tot després de que Rubió i Balaguer (1985) la situés com a fita de la història de la llengua i la literatura catalanes. Les poques referències que ha merescut acostumen aparèixer en panorames més o menys enciclopèdics de la tradició literària en llengua catalana, de manera que a dia d'avui no existeixen en la bibliografia fontanellana treballs que s'ocupin, de forma monogràfica, d'aquesta Lloa.

Els objectius del present estudi començaran per dur a terme una caracterització de la peça dins el gènere de la «lloa cortesana» i de la «lloa per a cases particulars», definides per Cotarelo, amb la finalitat de desprendre consideracions sobre el context $i$ el circuit teatral per al qual va ser concebuda

1 Aquest treball s'inscriu dins del Grup de Recerca Consolidat «Aula Música Poètica» de la Generalitat de Catalunya (2017 SGR 251) i dels projectes de recerca «Digital Música Poètica» (FFI2015-65197-C3-2-P) i «Teatro y obra poética completa (II) de Francesc Fontanella. Edición crítica» (FFI2015-70095-P), ambdós finançats pel MINECO.

SCRIPTA, Revista internacional de literatura i cultura medieval i moderna, núm. 11/juny 2018/pp. 178-199 ISSN: 2340 - 4841 doi:10.7203/SCRIPTA.11.12592 
l'obra, més enllà de les referències que fan els personatges a les dames barcelonines i que amb encert han posat de manifest investigadors com Rossich i Valsalobre (2011: 109) i Solervicens (2017: 385). No obstant això, el lloc central d'aquest estudi està dedicat a l'anàlisi de la sofisticada estructura dramàtica de la Lloa en relació a la música i al metateatre; en aquest sentit, s'aportaran conceptes poeticomusicals i exemples que serviran per formular noves hipòtesis de lectura que permetran, en última instància, una millor valoració crítica de l'obra de Fontanella.

\section{Teatre cortesà d'avantguarda, fora del circuit comercial}

Una de les característiques generals de la lloa, en tant que gènere dramàtic breu que obre les festes teatrals, és l'establiment d'una connexió directa amb els espectadors, a qui es convida a endinsarse en el món ficcional proposat i a qui són mostrades les cuines teatrals abans de servir el plat principal. Si l'art del segle XVII frueix per se trencant la quarta paret, podríem dir que la lloa és el gènere breu que més s'adiu amb la sensibilitat barroca i Fontanella no desaprofita l'ocasió en l'obertura de la seva Tragicomèdia. L'espectacularitat metateatral, la complexitat d'aquestes peces -en argument, llenguatge poètic, escenes, personatges, espais i temps- i la intenció d'esbalair l'espectador a través de la vista i de l'oïda augmenta considerablement en les obres dirigides al públic il lustre de la cort, motius pels quals podem afirmar, encara que no se sàpiga l'indret on representà Fontanella, que la Tragicomèdia està dissenyada per representar-se davant d'aquesta minoria social. Estem, per tant, davant d'una peça de teatre eminentment cortesana, per molt que puguem trobar en el text concessions al teatre comercial, explicables per la pròpia fórmula de l'Arte nuevo de Lope de Vega a la que tots els públics barcelonins estaven avesats ${ }^{2}$. Francesc Fontanella no sols està reivindicant un teatre profà modern en català sinó que, apujant el llistó de la dignificació de la llengua, fa una proposta de literatura dramàtica culta capaç de competir amb els espectacles fastuosos que es podien veure coetàniament a les principals corts del continent. Un mateix Zeitgeist europeu explica, d'una banda, la inauguració l'any 1640 de l'esplendorós Coliseo del Buen Retiro a Madrid, i d'una altra, les propostes dramàtiques de Fontanella a Barcelona en els mateixos temps.

Dintre del gènere en qüestió, la categoria de «lloa cortesana» o «lloa palatina» es reserva per aquelles que es distancien de la norma comú caracteritzada per la senzillesa (Spang 1994: 13). En el cas fontanellà, en lloc de ser una breu introducció d'una sola escena, amb un o dos personatges, la lloa està composta, com a mínim, per tres escenes -de gran complexitat argumental, pel que acostuma a ser una lloa ordinària-i nou personatges, a més del concurs d'elements visuals i musicals d'alta volada. No hi ha dubte, doncs, que ens trobem davant d'una lloa cortesana, encara que, si seguim la tradicional classificació de lloes de Cotarelo (2000), apareix una altra categoria en què

2 Un cortesà de rang com Barthélemy Joly, conseller del rei de França Enric IV, en llur visita a Barcelona l'any 1603, per més que freqüentés les elits locals, només va destacar l'èxit d'un dramaturg a la ciutat comtal: Lope de Vega (Miquel 1967: 14). 
Gaston Gilabert. L’èxtasi poètic de Fontanella: metateatre i música a la Lloa per la Tragicomèdia pastoral d'amor, firmesa i porfia

també podria encaixar, la «loa para casas particulares», que Spang qüestiona i finalment decideix incloure dins de les cortesanes (1994: 18), com un subtipus més del mateix fenomen:

\begin{abstract}
Los términos con los que se designa la loa palaciega varían: se llama también loa cortesana, loa de fiestas reales... Debe figurar igualmente en este lugar la loa para casas particulares -término lanzado por Cotarelo- dado que la diferencia entre la loa palaciega y la de casas particulares es más bien de cantidad y no de calidad, es decir, tanto el contenido como la forma y la escenificación guardan las mismas características básicas que la loa palaciega sólo que se adaptan a las posibilidades técnicas y pecuniarias del particular que las encargaba.
\end{abstract}

La Casa Gralla, fastuós palau renaixentista dels marquesos d'Aitona al carrer Montcada, havia estat expropiada durant la Guerra dels Segadors i, durant el breu virregnat francès, el lloctinent de Catalunya, Philippe de La Mothe-Houdancourt, l'havia emprat com a lloc de representacions teatrals cortesanes amb l'assistència de la noblesa catalana. No sabem del cert quina continuïtat va tenir com a espai performatiu, però si tenim en compte les característiques del ballet de cour que documenta Aznar (2014) l'any 1644, sembla evident que disposava de l'espai i els requeriments tècnics necessaris per a la representació d'obres que, com la Tragicomèdia, combinaven poesia, música i dansa. Malauradament, però, la qüestió dels espais teatrals cortesans a la Barcelona de la dècada de 1640 resta encara per estudiar a fons i disposem de molt poques dades, per la qual cosa, ara per ara, la possibilitat que l'obra de Fontanella fos efectivament representada en aquest palau, malgrat que és versemblant, només pot ser apuntada com una hipòtesi.

A partir de les referències textuals i paratextuals de tot el conjunt de la Tragicomèdia és impossible saber del cert l'any de llur representació així com el lloc escollit, que podria dependre del context. No sabem, per tant, si l'obra de Fontanella està pensada per a representar-se en l'indret per antonomàsia que acull habitualment representacions teatrals, la Casa de les Comèdies de la ciutat, o bé per a muntar-se en un palau, acadèmia o casa aristocràtica particular preparada ex professo per a l'ocasió. Ens sembla més plausible aquesta segona hipòtesi perquè, a part de les polítiques d'homogeneïtat de la monarquia hispànica en temps del comte-duc d'Olivares i de la diglòssia creixent a Catalunya en favor del castellà, tots els testimonis d'arxiu i notícies que conservem de representacions a la Casa de les Comèdies fan referència en exclusiva als èxits del teatre del Siglo de Oro en llengua castellana. Creiem que la Tragicomèdia està pensada per a un circuit alternatiu a l'oficial i comercial per on passaven aquelles companyies itinerants amb epicentre a la cort de Madrid i que és a aquesta altra noblesa catalana a qui va destinada la cèlebre defensa que fa Fontanella de la literatura catalana tant al Vexamen -que anomena «castellans fingits» als poetes catalans que canvien de llengua per al registre literari culte (Brown 1987: 229)- com a la Lloa. En aquest darrer cas, la màscara pastoral de Fontanella, Fontano, es queixa (vv. 255-258) ${ }^{3}$ :

3 Tots els versos citats de les obres dramàtiques de Fontanella provenen de l'edició de Maria Mercè Miró (Fontanella, 1988). 
Gaston Gilabert. L’èxtasi poètic de Fontanella: metateatre i música a la Lloa per la Tragicomèdia pastoral d'amor, firmesa i porfia

\author{
senten que sols se aplaudesca \\ lo llenguatje castellà, \\ quant la catalana musa \\ és tant dolsa, és tant suau
}

Creiem, amb Rossich (2001: 70), que «la moda barroca havia imposat els temes i la llengua castellana, i Fontanella es proposa intervenir en aquell cenacle per inaugurar el teatre culte en català.». En el mateix sentit, el personatge de Guidèmio respon amb el cèlebres versos que Jordi Rubió i Balaguer (1985: 216) va treure de l'oblit i restaurar ${ }^{4}$ per a la història de la literatura catalana (vv. 307-310):

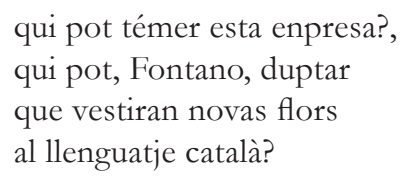

Hom podria rebatre la hipòtesi d'una representació particular per a famílies nobles catalanes citant determinades acotacions i efectes especials per a la vista i per a l'oïda presents en la Lloa i en la Tragicomèdia, però no hi cap d'ells que no pugui fer-se en una estança privada. Només cal llegir el testimoni del Poema anaforic (Tegell 1989) sobre els espectacles fastuosos que es van representar a una casa noble del carrer de Montcada, aproximadament tres dècades després de la mort de Fontanella, per a tenir una idea de les grans possibilitats escèniques fora de l'àmbit comercial oficial, amb el concurs de la noblesa local barcelonina i de la llengua catalana. Qualsevol dels palaus d'aquest carrer i d'altres indrets de la ciutat podrien haver acollit l'obra en qüestió.

\title{
3. La Lloa per la Tragicomèdia com a anti-lloa
}

Si la historiografia de la sarsuela i l'òpera hispàniques proposa com a primers llibretistes els dramaturgs del Siglo de Oro Juan de Tassis i Lope de Vega, caldria reivindicar Francesc Fontanella dins la història del teatre musical en llengua catalana. Per la textura poeticomusical de les seves dues grans obres dramàtiques, la Tragicomèdia -amb totes llurs peces dramàtiques breusi Lo desengany, podem afirmar que la música era un pilar fonamental en la pròpia concepció d'espectacle teatral. El desig d'experimentació quant a gènere és palès tant en les parts explícita i implícitament cantades de totes les seves obres dramàtiques com en la definició sui generis que fa ell mateix en boca d'un personatge de Lo desengany (vv. 329-332):

\footnotetext{
4 Una interpretació actual d'aquest capítol de la historiografia catalana es pot trobar a l'obra de teatre L'esperit del llibre, representada a l'Institut d'Estudis Catalans l'any 2015, on es reivindica la figura de Jordi Rubió, personatge protagonista que apareix citant aquests mateixos versos de Fontanella (Gilabert 2015A: 86).
} 


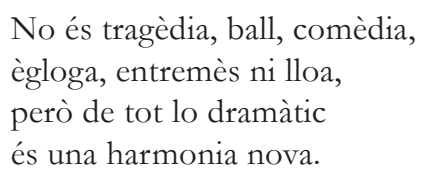

També la Lloa «sobrepassa els límits del gènere» i s'assembla més a un «entremès cantat» (Miró 1988: 22), de manera que, per la importància funcional de la música, podria molt ben ser l'obertura d'una òpera bufa, de la que seria una expressió succinta. És simptomàtic que Fontanella faci servir una terminologia similar en Lo desengany $i$ en la Lloa per la Tragicomèdia per destacar la novetat de la seva proposta dramàtica: cal posar al costat l'«harmonia nova» de la primera amb la «nova ermonia estraña» de la segona, relacionada aquesta, de manera més clara, amb la música (v. 142). Si cervantí podria ser el model de l'ovillejo que inclou la Lloa, cal posar també junts Cervantes i Fontanella a propòsit de dos textos breus introductoris profundament innovadors: els previs al Quixot i a la Tragicomèdia, respectivament. Com el seu polèmic precedent ${ }^{5}$, la peça breu de Fontanella és en realitat una anti-lloa, ja que es nega a sí mateixa i, paradoxalment, és denegant-se que existeix. Al final de la Lloa Mireno pregunta «Tindrà loa la Comèdia?» i Fontano respon «Mireno, no la tindrà» (vv. 323-324) i d'aquesta manera sembla que Fontanella cremi el pont del gènere pel que ha transitat fins aquell moment ${ }^{6}$. També seria anti-lloa en el sentit que la peça que aparentment tenien assajada ha quedat subvertida i anul lada per la pròpia peça, com més endavant s'explicarà.

La Tragicomèdia i Lo desengany són dues clares apostes d'avantguarda pel que fa al teatre profà culte, dos experiments poeticomusicals propers a l'òpera bufa i dues realitzacions radicalment inèdites a Catalunya i amb elements que també ho són en relació a Espanya i a Europa. No obstant això, Miró (1988: 32-33) exclou la festa teatral de la Tragicomèdia d'aquestes tres característiques, que només concedeix a la segona obra dramàtica.

Malauradament no ens han arribat les partitures teatrals de cap de les peces de Fontanella, de la mateixa manera que succeeix amb la gran majoria de música teatral peninsular dels segles XVI i XVII, però, per múltiples indicis, és innegable que el poeta barceloní tenia una alta sensibilitat musical i que treballaria estretament amb músics i compositors. La pèrdua d'aquest patrimoni musical, que de vegades va acompanyada per l'absència d'acotacions en la font literària, ha comportat que la crítica contemporània llegeixi com a versos declamats escenes que, en realitat, en el seu dia constituien encisadors passatges musicals, error que es tradueix en una comprensió equivocada de la situació dramàtica, dels personatges implicats i de la trama en què s'insereixen. Davant d'aquest perill

\footnotetext{
5 Una reflexió sobre gènere i anti-gènere a propòsit del pròleg del Quixot pot llegir-se a Genette (1987: 172-177).

6 Aquest caràcter metaliterari tan barroc de Fontanella, si bé apareix de forma extrema a la Lloa, també és present a les altres peces de la festa teatral, inclòs el propi text de la Tragicomèdia, on, en un passatge del tercer acte (vv. 31663170), Posimico es creu Música-musa i pretén influir en Fontano-Fontanella per canviar l’acció dramàtica i li demana: «aguarda't un poc, espera, / deixa'm almanco casar / ans de acabar la comèdia» a la qual cosa respon el noble pastor: «Calla, que ya és acabada», encara que quedi un altre torn d’intervencions després.
} 
freqüent, cal que el filòleg operi indiciàriament i que no caigui en el parany de la vis attractiva que té el text literari en una font literària, de la mateixa manera que el musicòleg, llegint un cançó teatral en una partitura, no ha de caure en el parany de pensar en l'autonomia musical de la composició. En el món de les arts escèniques de l'Edat Moderna, dramaturgs i compositors concebien la poesia i la música com arts agermanades, per més que les fonts literàries i les fonts musicals de la mateixa peça dramàtica es conservessin per separat.

Des d'aquestes línies farem una nova lectura de la Lloa de Fontanella per demostrar-ne la natura d'experiment poeticomusical i defensar que s'adiu millor a l'àmbit cortesà. Així mateix, presentarem una sèrie d'arguments que ens fan pensar que caldria llegir com a cantats un conjunt de versos que fins avui es llegien com a declamats i que pensem que caldria tenir en consideració, també, de cara a la lectura d'altres obres dramàtiques i poètiques del mateix autor.

El primer pas és fer un esquema d'estrofes mètriques per analitzar-ne els canvis, perquè, lluny de ser decisions poètiques atzaroses, amb freqüència obeeixen a canvis estilístics amb la voluntat o bé d'imprimir un to determinat o bé d'encastar-hi materials poeticomusicals, però, en qualsevol cas, el ritme dramàtic es veu alterat; res que no sabessin els propis dramaturgs, atès que una característica del regne còmic de l'Arte nuevo és la polimetria i el mateix Lope ja assignava la preferència de determinades estrofes a determinades situacions dramàtiques. Aquests canvis bruscos als textos teatrals de l'Edat Moderna fins i tot han establert una moda en la crítica filològica contemporània d'àmbit hispànic, que sovint busca unitats de divisió del text inferiors a la de l'acte o jornada però més poèticament significatives que la d'escena o quadre: es tracta de l'anomenada teoria de la segmentació mètrica, no exempta d'abusos i, per tant, de crítiques ${ }^{7}$. Un dels punts febles d'aquesta teoria filològica és pensar en l'obra teatral, no com una matriu de signes diversos, sinó com a material purament literari, amb oblit o menyspreu dels ingredients musicals, ja que quan el filòleg detecta un canvi mètric degut als versos cantats d'un to teatral, fa com si no hi fossin, perquè, de manera automàtica, els considera subordinats a una altra estrofa mètrica (Gilabert 2015B: 76-77). Des d'aquest pressupòsit de subordinació d'un material que jutgen aliè és impossible, per exemple, que considerin que el text cantat per un personatge pugui condicionar el desenvolupament de l'acció o les estrofes mètriques que venen a continuació.

La Lloa de Fontanella és un bon exemple de fenomen que escapa a la lògica de la teoria de la segmentació mètrica, ja que és precisament una cançó la que determina un canvi d'estrofa amb implicacions significatives en l'argument de la peça. Com es veu al següent quadre, la cançó «Los pastors y las pastoras / del Besòs y Llobregat» (vv. 149-160) representa un punt d'inflexió en l'estructura mètrica de tot el text, que passa de la rima femenina del romanç en à-a, a la rima masculina del romanç en à. Aquesta darrera estrofa que inaugura la música en el moment central de la Lloa, és la que, després d'aquesta escena poeticomusical que també inclou un ovillejo parcialment cantat, quedarà fixada per tota la resta de personatges fins el final de la peça.

7 Sobre aquesta teoria poden veure's els treballs de Vitse (1998) i d'Antonucci (2000 i 2010). 
Gaston Gilabert. L’èxtasi poètic de Fontanella: metateatre i música a la Lloa per la Tragicomèdia pastoral d'amor, firmesa i porfia

Taula 1

\begin{tabular}{|l|l|l|}
\hline \multicolumn{1}{|c|}{ Versos } & \multicolumn{1}{|c|}{ Estrofa mètrica } & Personatge «Música» explícit \\
\hline $1-148$ & Romanç femení en à-a & \\
\hline $149-160$ & $\begin{array}{l}\text { Romanç masculí en à } \\
\text { («Los pastors y las pastoras / del Besòs y Llobregat») }\end{array}$ & «Música» (vv. 149-160) \\
\hline $161-170$ & $\begin{array}{l}\text { Ovillejo } \\
\text { («Qual és lo assumpto major?») }\end{array}$ & «Música» (vv. 162, 164 i 166) \\
\hline $171-376$ & Romanç masculí en à & \\
\hline
\end{tabular}

Aquesta fixació definitiva de la mètrica que es produeix amb la cançó té un correlat amb la fixació definitiva del tema de la Tragicomèdia: és en aquest moment on la Musa-Música està expressant a Fontanella-Fontano quin assumpte ha de tenir l'obra teatral - «Estas, Fontano, an de ser / lo objecte vuy remontat (...)» (vv. 157-158)-. De la mateixa manera, també la música arribarà per quedar-s’hi i acompanyarà molt probablement diversos versos de la darrera seqüència del romanç masculí en à, encara que no estigui revestida del caràcter metafísic de l'escena central de la Lloa. Fontanella, per dotar la música d'una funció sobrenatural, al legoria de la pròpia inspiració poètica, es val dels següents recursos: inclou la «Música» com un locutor més, encara que sigui un personatge abstracte; fa que aquest només es manifesti acústicament, ocultant-lo als ulls de l'auditori -«canta la Música dintre» (v. 149 acot.)-; estableix una connexió directa amb el personatge de Fontano, anomenant-lo pel nom (v. 157) en la seva cançó-exhortació i mantenint amb ell un diàleg de preguntes i respostes a l'ovillejo; i, finalment, tota la seqüència poeticomusical es dona en un context de suspensió de la racionalitat, en aquest cas, Fontano està somniant i, com si fos somnàmbul, interactua amb la Música mentre dorm. Malgrat que aquestes quatre característiques de l'escena musical central no es manifestin en el desenllaç de la Lloa i en altres escenes de les obres dramàtiques de Fontanella, no vol dir que en aquestes no hi hagi música, al contrari: només vol dir que la música no té una funció metaliterària i metafísica de manera tan radical.

Hem vist com la divisió en estrofes mètriques emfasitza el caràcter central de la música en la Lloa i al mateix resultat arribaríem si féssim una clàssica divisió en escenes o quadres, prenent com a criteri l'entrada i sortida de personatges. La primera escena (vv. 1-148) correspon en exclusiva a la parella de personatges graciosos Posimico i Cassòlio, quadre que coincideix plenament amb tota la primera seqüència mètrica de romanç femení en à-a. El tema d'aquesta primera part és el somni grotesc que ha tingut Posimico i que Cassòlio ajuda a interpretar en un exercici d'hermenèutica que accentua el caràcter metateatral de la Lloa, aquí al servei de l'element burlesc. És evident que Fontanella segueix la lògica del contrast i del clarobscur perquè en l'escena segona veurem Fontano somniant mentre la Música, revestida de sacralitat, li dicta cantant el destí. Un cop despert, en la tercera escena, trobem un altre exercici hermenèutic, però ara el farà el protagonista amb els diversos pastors que l'acompanyen. Veiem clarament tres escenes diferenciades tant pels personatges com pels temes i ambients dramàtics que aquests inspiren: 
Gaston Gilabert. L’èxtasi poètic de Fontanella: metateatre i música a la Lloa per la Tragicomèdia pastoral d'amor, firmesa i porfia

Taula 2

\begin{tabular}{|l|l|l|l|}
\hline \multicolumn{1}{|c|}{ Escena } & \multicolumn{1}{|c|}{ Personatges } & \multicolumn{1}{c|}{ Motius } & \multicolumn{1}{c|}{ To } \\
\hline I (vv. 1-148) & Posimico i Cassòlio & $\begin{array}{l}\text { Interpretació del } \\
\text { somni de Posimico }\end{array}$ & Baix/Còmic \\
\hline II (vv. 149-178) & Música i Fontano & Somni de Fontano & Elevat/Tràgic \\
\hline III (vv. 179-376) & $\begin{array}{l}\text { Fontano, Mireno, Castàlio, Tirsis, Morano, } \\
\text { Guidèmio, Posimico i Cassòlio. }\end{array}$ & $\begin{array}{l}\text { Interpretació del } \\
\text { somni de Fontano }\end{array}$ & Híbrid / Tragicòmic \\
\hline
\end{tabular}

La sensació d'una arquitectura metateatral en expansió referida a aquesta peça augmenta a mesura que se n'examinen les parts. Si aquest gènere breu és l'avantsala de l'obra principal, podria semblar, per la primera escena de la Lloa, que l'obra dramàtica que els espectadors esperen serà fonamentalment humorística. Com si fos un precedent llunyà de Luigi Pirandello, Francesc Fontanella està jugant amb l'horitzó d'expectatives, i és que Posimico i Cassòlio venien a una comèdia, en el sentit més baix, i no a una tragicomèdia, tal i com es desprèn de la primera escena, on el primer diu (vv. 57-60):

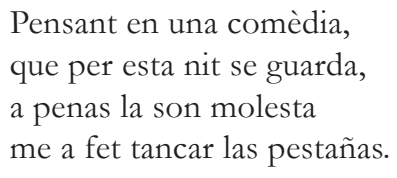

A continuació explica l'argument de la comèdia somniada, on ell, «transformat en mico» (v. 75) robava la més alta corona de llorer a Guidèmio, Fontano, Mireno, Menalcas, Morano, Tirsis, és a dir, que l'element còmic representat pel graciós animalitzat, passava per davant de les històries tràgiques de què són portadors la resta de personatges. En aquesta suposada premonició argumental, també esmenta l'aparició de la figura còmica per antonomàsia del teatre del Siglo de Oro, «Joan Rana» (v. 86). Cassòlio realitza l'exercici hermenèutic del somni misteriós i aplaudeix el triomf de l'element jocós (vv. 117-124) de l'obra que veuran els espectadors:

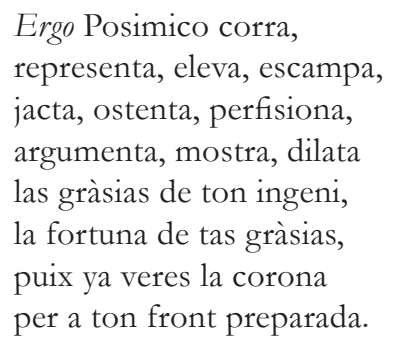

De fet, després se'ns diu que Fontano s'havia quedat adormit assajant la peça còmica original, «descontent de la comèdia / que avia de repassar» (vv. 231-232) i, els altres personatges, quan el veuen parlar en somnis, es pensen que segueix repassant el seu paper còmic: «Què tens, Fontano, què tens? / És axò lo repasar» (vv. 187-188). Els espectadors estan esperant i la resta d'actors frisen 
Gaston Gilabert. L’èxtasi poètic de Fontanella: metateatre i música a la Lloa per la Tragicomèdia pastoral d'amor, firmesa i porfia

per començar la comèdia: «O Fontano, estàs a punt?», «Mira, Fontanto, que és tart!» $\mathrm{i}$ «Es per anit la comèdia?», «O la guardam per damà?» (vv. 179-182). És un encert del dramaturg fer que es trenqui aquest horitzó d'expectatives quant a gènere durant la segona escena, on les muses i la Música irrompran en el somni de Fontano-Fontanella per fer-li obrir els ulls al fet que la llengua catalana també és susceptible de produir teatre culte i no només còmic o burlesc. En virtut d'aquesta epifania, Fontano no tindrà cap més remei que canviar l'obra còmica que tenien pensada per a representar aquella nit i improvisar-ne una altra. Es tracta d'una violenta intromissió de l'element metafísic en la quotidianitat i per això Fontanella necessita l'element oníric com a base operativa versemblant i el vehicle musical per la seva capacitat de suggestió. La resolució es pot veure al desenllaç de la Lloa, atès que la tercera escena és ja una barreja tragicòmica dels elements i personatges baixos de la primera escena, amb l'element elevat i el personatge de Fontano presents en la segona.

En aquesta peça fora del comú, el poeta barceloní concedeix a la Música un paper clau i de gran virtuosisme. No només és la causant del canvi de rumb en l'obra per representar, sinó que a més és l'encarregada de foragitar abruptament els personatges graciosos de la primera escena, com si la musa catalana no pogués sofrir més l'encasellament en la tendència popular. La primera aparició de l'element sonor no és doncs amb la peça vocal «Los pastors y las pastoras / del Besòs y Llobregat» (vv. 149 i ss.) sinó amb un preludi instrumental que té la doble funció d'introduir la segona escena i de forçar l'extinció del món còmic que havien representat en exclusiva durant la primera escena Posimico i Cassòlio (vv. 141-146).

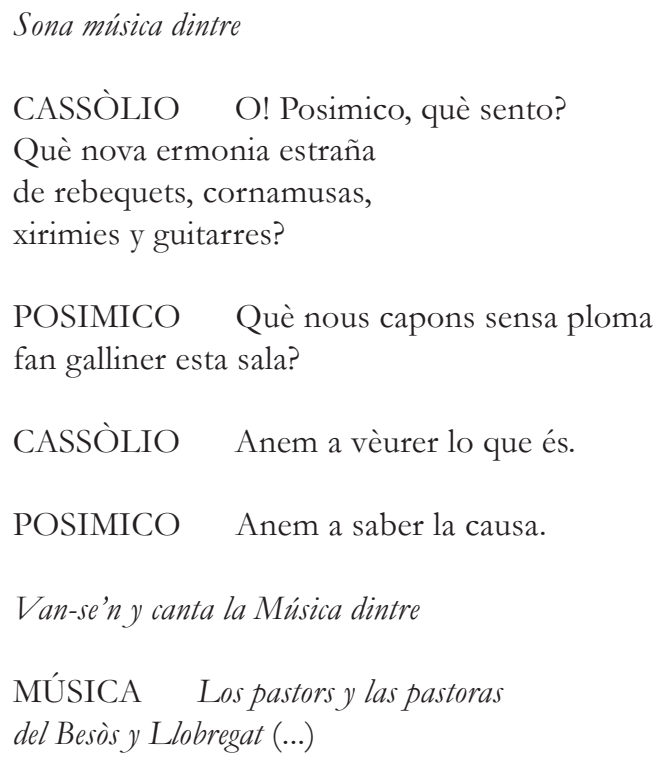

Aquesta «nova ermonia estraña» i produïda per «nous capons sensa ploma» sobta els graciosos, que la tenen per novetat aliena a la norma habitual. Seduïts per la curiositat que suposa una forma nova, els dos personatges marxen sense saber que la proposta dramàtica implica que perdin la centralitat en tant que graciosos. És en aquest trànsit entre la primera i la segona escena on comença el gir 
Gaston Gilabert. L’èxtasi poètic de Fontanella: metateatre i música a la Lloa per la Tragicomèdia pastoral d'amor, firmesa i porfia

innovador de la lloa fontanellana. A la tercera jornada, tornarem a veure Posimico i Cassòlio, però ara ja compartint espai dramàtic i elements configuradors de gènere amb altres personatges i elements.

\section{El clímax experimental: la música fertilitza el vers}

A la segona de les tres escenes, clarament delimitada per dues acotacions que impliquen canvis de personatges en escena, se situa el moment climàtic de la Lloa. Encara que sigui l'escena més curta de la peça i que faci de frontissa entre el que anava a ser en un primer moment i el que serà definitivament, constitueix la seqüència més intensa pel que fa a complexitat significativa; de fet, en els seus vint-i-nou escassos versos es pot llegir tota una declaració d'intencions dramàtiques.

Des del mateix lloc ocult d'on havia començat el preludi instrumental de rabequets, cornamuses, xeremies i guitarres, els músics començaran a executar vocalment la cançó «Los pastors y las pastoras / del Besòs y Llobregat». És possible que la «nova ermonia estraña» que això suposa pels personatges foragitats tingui a veure, en aquest joc de miralls fontanellà, no només amb l'experiment de gènere i llengua que està fent el dramaturg, sinó també amb la concreta harmonització musical que s'està interpretant mitjançant la consonància d'instruments rústics i populars. Els espectadors devien quedar bocabadats escoltant com uns instruments associats per costum a allò baix, poden harmonitzar-se i oferir un producte adequat a l'oïda culta de l'il lustre auditori, de la mateixa manera que està succeint amb la llengua catalana pel teatre profà culte. Són aquests instruments i llengua els que, amb orgull i caràcter d'avantguarda, emprarà la Música com a portaveu de les divinitats inspiradores en l'escena més elevada de la Lloa. No en va Fontano descriurà aquest híbrid poeticomusical mig popular mig culte com «festivament sonora / armonia celestial» (vv. 235-236).

La lletra cantada introdueix en el subconscient de Fontano dorment els tres temes que la nova obra reformada ha de tenir: «la força suau» de «las fletxas de Cupido» (vv. 151-152), la «firmesa constant» (v. 156) i la «desditxada porfia» (v. 155) o, dit d'altra manera, amor, firmesa i porfia. També indica quin ha de ser l'espai on es desenvoluparan aquestes altes passions, una localització real idealitzada per la ficció pastoral, tan fictícia i tan real com pugui ser el Tajo d'on Garcilaso feia sortir les nimfes o l'Arcàdia de Sannazaro. Mitificar les riberes del Besòs i del Llobregat respon també a la mateixa operació de dignificar amb accions elevades l'element rústic i popular, segons la moda d'avantguarda de les corts europees més modernes. Res a veure, doncs, amb el somni del graciós de la primera escena, on aquests dos rius i altres elements argumentals apareixien com a teló de fons d'una acció risible. Es manifesti l'argument de la Tragicomèdia a la Lloa en forma ridícula -en boca de Posimico- o seriosa -en boca de la Música i Fontano-, no podem compartir les paraules de Miró (1988: 22) segons les quals, «ni la Lloa ni l'Entremès no donen, però, l'argument de la Tragicomèdia», ja que, per a aquesta investigadora, l'únic element en comú seria el repartiment de personatges, motiu pel qual identifica aquesta peça breu amb el gènere de «lloes de presentació de 
companyies o de revista de personatges». Ans al contrari, creiem que Fontanella va molt més enllà dels objectius que persegueixen aquestes tipologies de lloes i exposa l'argument de la Tragicomèdia sobretot en el moment climàtic de la segona escena en què la Música proposa quins han de ser els personatges, l'espai i els temes que haurà d'abordar. Certament no desenvolupa en la seva cançó els esdeveniments de l'acció dramàtica, però fa una primera aproximació de l'argument, que després repeteix i amplia la Lletra que se canta antes de representar la Comèdia, que Miró anomena «colofó de la lloa» (1988: 24) i que anticipa, fins i tot, els desenllaços que tindran diversos personatges a la Tragicomèdia que és a punt de començar.

Tres són també les parts en què es pot subdividir aquesta breu escena poeticomusical, perquè clarament està composta per tres ingredients diferenciats: la cançó «Los pastors y las pastoras / del Besòs y Llobregat» que interpreta la Música, l'ovillejo distribuït en versos que canta la Música i declama Fontano, i, al final, un romanç de vuit versos conclusius que corresponen únicament al protagonista masculí. Un quadre sinòptic posa de manifest la rellevància que té la Música en l'evolució de la Lloa i la seva natura contaminant: després d'aparèixer en l'espectre sonor, res no tornarà a ser igual. De moment ja hem vist com les muses en forma de Música han imposat un canvi de tema, de gènere i de to, però també un canvi d'estrofa: el primer vers de la cançó trenca amb la mètrica anterior i Fontanella fa, d'aquesta proposta de la divinitat, la forma estròfica de tota la tercera escena fins el final de la peça ${ }^{8}$.

Taula 3

\begin{tabular}{|l|l|l|l|l|}
\hline Escena & Versos & Personatges & Estrofa mètrica & Expressió \\
\hline I & $1-148$ & Posimico i Cassòlio & Romanç de rima femenina à-a & Declamat \\
\hline \multirow{2}{*}{ II } & $149-160$ & Música & Romanç de rima masculina à & Cantat \\
\cline { 2 - 5 } & $161-170$ & Fontano i Música & Ovillejo & $\begin{array}{l}\text { Híbrid cantat i } \\
\text { declamat }\end{array}$ \\
\cline { 2 - 5 } & $171-178$ & Fontano & Romanç de rima masculina à & Recitatiu? \\
\hline III & $179-376$ & $\begin{array}{l}\text { Fontano, Mireno, Castàlio, } \\
\text { Tirsis, Morano, Guidèmio, } \\
\text { Posimico i Cassòlio. }\end{array}$ & Romanç de rima masculina à & $\begin{array}{l}\text { Híbrid Recitatiu, } \\
\text { cantat i declamat? }\end{array}$ \\
\hline
\end{tabular}

Aquesta fertilització contaminant de la Música també s'aprecia en la pròpia estructura de l'ovillejo, que es revela com la millor estrofa que podia seleccionar Fontanella per a mostrar la lluita interior que suposa la reforma dramàtica suggestionada o autosuggestionada. Al romanç cantat previ, les muses havien fixat la mètrica, l'espai, el tema i el gènere a la manera d'una invocació per la qual

8 Aquest mateix recurs poeticomusical, pel qual la música fertilitza el vers declamat i en determina el desenvolupament de la forma, es pot apreciar amb claredat en l'obra del darrer dramaturg reial de la dinastia dels Habsburg, Francisco Bances Candamo. Pot veure's, per exemple, el que succeeix a la seva comèdia Sangre, valor y fortuna ( Gilabert 2017B: 216-224). 
Gaston Gilabert. L’èxtasi poètic de Fontanella: metateatre i música a la Lloa per la Tragicomèdia pastoral d'amor, firmesa i porfia

s'inocula una idea al dorment i després, a l'ovillejo, veiem el procés d'interiorització tant del contingut de l'obra, com del mode d'expressió poeticomusical. La hipnosi és efectiva en tant que Fontano es veu obligat a canviar l'obra teatral que assajava i a participar en una estructura poètica parcialment cantada.

\author{
FONTANO Qual és lo assumpto major? \\ MÚSICA Amor. \\ FONTANO Dóna Amor a nostra enpresa? \\ MÚSICA Firmesa. \\ FONTANO Dóna a la esperansa mia? \\ MÚSICA Porfia. \\ FONTANO Així Febo, axí Talia, \\ que $l$ s versos inspiraran, \\ per digne assumpto tindran \\ Amor, Firmesa y Porfia.
}

Es tracta d'un motlle estròfic que conjuga l'efecte metafísic de l'eco -cal tenir present que els músics romanen ocults- que Fontanella fa cantat per simbolitzar, per una part, que és la divinitat qui li dicta les respostes amb aquest llenguatge extraordinari que és la música i, per una altra, que les solucions a les seves preguntes ja estaven dins seu, doncs l'eco es fabrica amb la pròpia veu'. És necessari recordar que totes les dades temàtiques que dona l'ovillejo i que Fontano resumeix en els darrers quatre versos, ja havien estat exposades en els dotze versos de la cançó prèvia, per tant, el poeta barceloní està repetint informacions en les dues primeres parts d'aquesta escena, estratègia que fa que com a espectadors i lectors parem més atenció en la forma que en el contingut. El que abans era un desig exclusiu de la divinitat, ara és compartit per Fontano en l'ovillejo i, en la tercera part d'aquesta breu escena quedarà el protagonista en soledat per a defensar la nova proposta. Es tracta d'un recurs poètic extraordinari per explotar el símbol del procés d'inspiració poètica en tres etapes. Es tracta d'un «èxtasis de poeta», com s'especula en el debat entre els companys de Fontano (v. 197).

Com a lògica conseqüència d'aquest recurs poeticomusical en forma d'epifania pel protagonista, podríem aventurar la hipòtesi que la sobtada transformació proposada per la Música-Musa i acceptada sense dubtar per l'hipnotitzat, també afecta al mode d'expressió, que seria pròpiament

\footnotetext{
9 Caldria posar en relació aquest ovillejo de Fontanella amb altres poemes amb eco, en llengua catalana i del mateix context de la Guerra dels Segadors; per exemple, en el recull poètic d'Anna M. Torrent poden llegir-se composicions d'aquest tipus, encara que amb clares finalitats propagandístiques, com les que responen als íncipits «Diu-se qu és, lo Comte Duch, / un ruc» (1984: 85-86) i «Què us apar de aquesta guerra? / Pobre terra» (1984: 87).
} 
un recitatiu operístic, a mig camí entre el cant i la declamació. La forma híbrida de declamat musical seria la més adient des de la part final de la segona escena, on Fontano es troba sol, fins el final de la Lloa, encara que en la tercera escena el recitatiu aparegui entre altres recursos musicals, amb l'objectiu d'acabar la peça alhora enlluernant els espectadors amb el desplegament artístic i oferint grans expectatives per a la Tragicomèdia. A aquesta sensació final sens dubte hi contribueixen també els vint-i-tres versos de la Lletra que se canta antes de representar la comèdia, l'epíleg de la Lloa que, sense formar-ne part stricto sensu, participa del mateix univers temàtic, poètic i musical, a banda de servir de descans pels personatges que inauguren l'acte primer de la Tragicomèdia, sobretot Fontano.

El recurs de l'eco, que Fontanella fa servir en aquesta elevada escena d'èxtasi poètic, es torna a repetir a l'Entremès, en boca del mateix personatge de la Música, però amb una finalitat burlesca. Si el somni de Fontano funcionava a la Lloa com a contrast del somni anterior de Posimico, torna a reproduir-se el mirall invertit. En efecte, havíem vist els dos passatges onírics amb la diferència afegida que la Música només havia dialogat directament amb el noble pastor i no pas amb el graciós, a qui no modificava la conducta. En una operació metateatral, les muses havien decidit canviar Fontano i el curs de la representació dramàtica en aquell diàleg mig cantat mig declamat i a l'Entremès la mateixa veu divina jugarà amb la identitat del graciós fent-lo creure que realment és un altre actor còmic, com «Joan Rana», entre d'altres. Cal que espectadors i lectors esperin, doncs, a l'entremès per completar el cercle de somnis i manipulacions cantades de la Música en relació als personatges alt i baix.

En l'esperat diàleg, el perjudicat pregunta ansiós «Y'm dic Posimico?» i la Música li respon cantant en eco quina serà la seva essència, «Mico», a la qual cosa es queixa la víctima «Cara tinch de mico, yo?» (vv. 287-288). Amb un nexe musical, el poeta barceloní connecta els tres actes de la Tragicomèdia amb llurs peces breus, lligam que a Lloa es produeix mitjançant els somnis de Fontano i Posimico, que neixen a l'obertura però es projecten a diferents indrets de la festa teatral. És a l'Entremès quan comprenem el somni hilarant que havia tingut el graciós a l'inici, on ell es transformava en mico i on apareixia també «Joan Granota». En termes metaliteraris, semblaria que aquesta acció grotesca hauria estat la peça principal de la comèdia de no haver intervingut a temps la Música per a canviar-ne el curs, introduint-se en el somni de Fontano i fent realitat allò que li ha fet somniar. Les imatges oníriques de Posimico només es poden fer realitat a l'Entremès, el gènere més escaient per a la seva proposta còmica i l'únic hàbitat en què la Música deixa que aquesta espècie de comicitat ho envaeixi tot.

\section{Agrupacions de música vocal}

Segons la hipòtesi desenvolupada en aquestes línies, el desplegament de recursos poeticomusicals de la Lloa passaria des d'una primera escena sense música protagonitzada pels graciosos, a una segona escena amb el punt d'inflexió del personatge de la Música, per acabar amb una tercera escena que, 
encara que no contingui cap acotació explícita que indiqui presència d'elements musicals, reuniria diferents elements formals i de contingut escampats al llarg de tota la peça; com si es tractés d'una correlació disseminativo-recol lectiva, tan típica dels sonets del Barroc, però també dels ovillejos, i es portés al nivell de l'estructura de la lloa. Així, la parella satírica de la primera escena que fuig davant la presència harmonitzadora de la música sublim i d'un Fontano amb atributs del déu que havia vençut Màrsies, torna a aparèixer al final, juntament amb la resta de personatges. La resolució tragicòmica i festiva de la lloa encaixa amb la lògica de juxtaposició pròpia de les composicions poètiques que acaben amb una recol lecció d'elements dispersos.

Una nova proposta de lectura és que almenys quatre dels personatges que apareixen a la tercera escena són cantants i que les seves intervencions podrien llegir-se íntegra o parcialment segons aquest mode d'expressió. Són Mireno, Castàlio, Tirsis i Morano, precisament els encarregats tant d'inaugurar la darrera escena com de concloure-la i, amb els últims versos, finalitzar la lloa i donar pas a la Lletra cantada que condueix al primer acte de la Tragicomèdia.

L'ordenació de les intervencions d'aquests quatre personatges suggereixen una disposició musical a quatre veus, tan freqüent en la poesia musicada del segle XVII i als escenaris del teatre castellà del Siglo de Oro. A diferència de les fonts musicals, les literàries no poden reproduir diferents veus que simultàniament expressin paraules diferents, de manera que una peça polifònica com la fuga o qualsevol encavalcament de veus sempre desafia el caràcter successiu de la lletra escrita, que transcriurà necessàriament com a versos consecutius tot allò simultani en part o solapat íntegrament.

En absència d'acotacions en el teatre de l'Edat Moderna cal tenir present una sèrie d'indicis per a rastrejar aquests dispositius musicals: l'aparició d'una agrupació de personatges que sempre van junts -normalment, quatre-; cadascun d'ells té assignada una repartició d'intervencions i quantitat de versos que obeeix a una lògica comú entre ells i diferent a la de la resta de personatges; les intervencions individuals amb diferents missatges - potser simultanis- responen o bé a una única funció i s'expressen de manera similar - per exemple, oracions exhortatives o repeticions de determinats mots- o bé es busca un clar contrast entre subgrups -seria el cas de dos cantants afirmant el que una altra parella nega ensems-; combinen ràpides expressions individuals -amb un o pocs versos cadascun, per torns- amb moments corals on s'expressen a la vegada. En el cas que l'agrupació sigui la tradicional de quatre individus, que hi hagi una marca textual que els esmenti amb el guarisme - (El 4», «A 4», «Los 4», etc.- i que inauguri o clausuri una escena, autoritza a considerar que la probabilitat que el passatge sigui musical sigui pràcticament una certesa. Una altra marca textual indiciària d'una estructura encavalcada a causa d'una temporalitat complexa d'impossible transcripció fora d'una partitura són els punts suspensius al final de cada curta intervenció. En tant que totes aquestes característiques es manifesten en el grup de personatges que apareix al tercer acte i que està compost per Mireno, Castàlio, Tirsis i Morano, proposo donar aquesta consideració, com a mínim a alguns dels passatges en què participen. Exemples d'aquestes característiques es poden veure en els següents fragments (vv. 179-204): 
Gaston Gilabert. L’èxtasi poètic de Fontanella: metateatre i música a la Lloa per la Tragicomèdia pastoral d'amor, firmesa i porfia

\begin{abstract}
MIRENO O Fontano, estàs a punt?
CASTÀlIO Mira, Fontano, que és tart!

TIRSIS És per anit la comèdia?

MORANO O la guardam per damà?

$[\ldots]$

TIRSIS Mira que ‘s queixa Guidèmio...

MORANO Mira que tots te aguardam...

MIRENO Sens dupte que està adormit...

CASTÀLIO Sens dupte que està somiant.

$[\ldots]$
\end{abstract}

LOS 4 O, Fontano!

FONTANO ¿Qui m perturba...

LOS 4 Desperta, desperta ya!

FONTANO $\quad .$. de aquest lloc ple de prodigis tranquil la serenitat? [...]

Sembla que al món on es desperta Fontano en el tercer acte s'han fet realitat els seus somnis musicals de fer un teatre profà culte: els seus companys ja el rebrien cantant a quatre veus. Aquesta agrupació vocal era coneguda simplement pel número quatre i, com a tal és definit pel Diccionario de Autoridades: «cuatro se llama en la música la composición que se canta a cuatro voces». Encara que no ens hagin arribat les partitures d'aquest quatre fontanella, sí han sobreviscut moltes peces d'aquesta mena a la península, que el lector curiós pot cercar, per exemple, al cançoner poeticomusical més important del segle XVII, el Libro de tonos humanos ${ }^{10}$. Els quatres més freqüents al teatre del Siglo de Oro són els denominats «cuatros de empezar» per inaugurar actes o escenes, però els dramaturgs de l'Edat Moderna també van fer servir quatres per concloure actes i escenes. A la peça breu fontanellana s'inicia la tercera escena amb els versos dels quatre personatges reproduïts anteriorment $i$, per concloure la lloa, es fa sortir de l'escenari a tots els personatges que han intervingut, excepte el conjunt vocal que, amb els seus versos molt probablement cantats, clausura l'obra (vv. 369-376):

10 Fins la data, Josa y Lambea han editat i publicat quatre volums del Libro de tonos humanos (Josa y Lambea 2000, 2003, 2005 i 2010). Un exemple més concret es pot trobar al quatre «Labradora de Loeches» (2000: 249). 


\title{
Gaston Gilabert. L’èxtasi poètic de Fontanella: metateatre i música a la Lloa per la Tragicomèdia
} pastoral d'amor, firmesa i porfia

\author{
Van-se'n Fontano, Guidèmio, Posimico y Cassòlio \\ MIRENO Y CASTÀLIO Y si las damas hermosas \\ estíman la voluntat... \\ MORANO Y TIRSIS Y si lo noble auditori \\ aplaudeix assumpto tant... \\ MIRENO Y CASTÀLIO poèticas flors coronen... \\ MORANO Y TIRSIS llorers síñan inmortals \\ las musas de Monjuïch, \\ los sisnes de Llobregat.
}

En aquest darrer cas, per la lògica seguida en tota l'escena i en altres dramaturgs, és probable que els darrers dos versos finals fossin cantats per «Los 4» ensems, a no ser que es tracti d'una imbricació polifònica més complexa de transcriure poèticament. Evidentment, l'existència de quatre actors amb aptituds musicals no impedeix que n'hi hagi d'altres, ni impedeix agrupacions i subgrups alternatius, com per exemple el duo que trobem en un altre moment de la tercera escena, on participen Fontano i Guidèmio (vv. 361-368) i que podria ser en recitatiu o plenament cantat amb diferents tessitures. Aquests són els darrers versos d'aquest passatge:

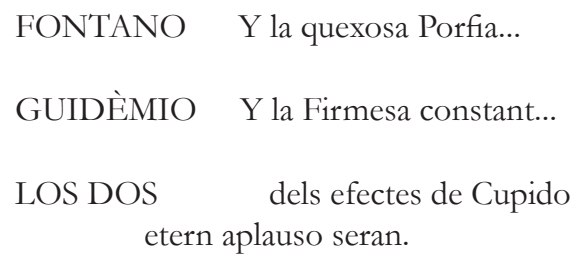

No ens ha d'estranyar que hi hagi tants cantants masculins entre els actors del repartiment; de fet sabem que hi són perquè en altres moments musicals del conjunt de la Tragicomèdia tornen a fer acte de presència. Per exemple, l'Entremès per la Tragicomèdia pastoral d'amor, firmesa i porfia comença amb un diàleg entre el graciós Posimico i la Música, personatges que ja havien aparegut a la Lloa, però seguidament apareixen sis endolats cantants que interpretaran un contrafactum burlesc de la famosa cançó que popularitzaria Lope de Vega a El Caballero de Olmedo. El poeta barceloní s'hauria fixat en una de les obres amb més importància funcional de la música, encara que quantitativament només compti amb dues cançons (Gilabert 2017A). És versemblant pensar que Fontanella hauria fet figurar, entre aquests sis cantaires de dol -a qui la caracterització i vestuari d'endolats no permetria veure la cara-, els quatre actors-cantants que havien interpretat els personatges de Mireno, Castàlio, Tirsis i Morano a la Lloa. Com una concessió al gust del públic en un gènere idoni per al descans dramàtic, aquests quatre personatges, juntament amb dos cantants més, executarien en disset versos (vv. 34-49) el contrafactum que comença d'una manera que deixa clara la relació de parentiu amb 
Gaston Gilabert. L’èxtasi poètic de Fontanella: metateatre i música a la Lloa per la Tragicomèdia pastoral d'amor, firmesa i porfia

la tradició i que remet a una cançó de moda que tot espectador devia conèixer per les múltiples reproduccions, versions i comentaris que se'n van fer a l'època (Rico 1981: 45-51 i 77):

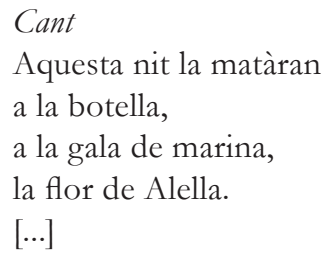

S’equivoca Maria Mercè Miró (1988: 24) suggerint que una única persona -concretament una actriu - fos la responsable exclusiva dels solos de l'obra de Fontanella i de la Lletra que se canta antes de representar la comèdia, perquè no té en compte ni altres actors que fan papers masculins i que tenen habilitats musicals, ni que la identitat de «Música» respon freqüentment a un personatge col lectiu, ni que majoritàriament executa el seu cant fora del camp de visió dels espectadors. Així ho evidencien les acotacions prèvies a la cançó de la Música «Los pastors y las pastoras / del Besòs y Llobregat», per exemple «sona música dintre» i, en el manuscrit 2794 de la Biblioteca de Catalunya, «Càntan dintre». També hi ha altres indicis de música col lectiva en altres passatges del conjunt de la Tragicomèdia, com a l'entremès, on «càntan tots» (v. 33 acot.) i veiem, en al lusions a un espai indeterminat on se suposa que assagen, els músics afinant els instruments -«Mes allí los músichs trèmpan»-i els cantants aclarint-se la veu -«Allí escúran los cantors» (vv. 80-81). Al final d'aquesta peça, Posimico es referirà a músics instrumentals i vocals quan demani a tothom que surti dels seus amagatalls per ballar sobre l'escenari: «Exiu donchs, exiu amichs, / sonau músichs y cantors. / Vaja de ball y de festa» (vv. 291-293).

Quan la Música com a interlocutora dialoga directament amb altres personatges, aquests el tenen també com a agrupació vocal, com és palès a l'intercanvi dialògic que manté la Música amb Fontano a la Lloa i amb Posimico a l'Entremès. En aquest darrer cas, el totpoderós personatge que simbolitza la inspiració poètica i que decideix bruscament el contingut de l'acció futura, fa befa de Posimico dient-li que la seva verdadera identitat és Joan Rana i ell contesta: «Yo, Joan Rana y Joan Granota? / Diuen molt bé los cantors» (v. 134-135); més tard es queixa contra la Música com a conjunt: «O, mal àjan los cantors!» / que conponent sas lisonjas, / mos sentits an desconpost» (vv. 275-278); i en el cas de la Lloa, quan la Música dictamina que els temes de la Tragicomèdia han de ser amor, firmesa i porfia, Fontano sembla respondre a un conjunt vocal amb presència masculina i femenina, ja que al final de l'ovillejo identifica la veu amb Apol lo i Talia (vv. 167-170):

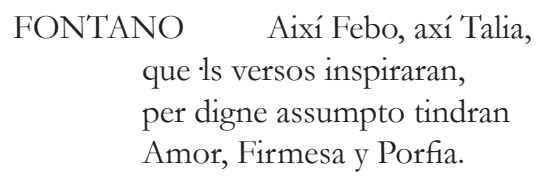


Gaston Gilabert. L’èxtasi poètic de Fontanella: metateatre i música a la Lloa per la Tragicomèdia pastoral d'amor, firmesa i porfia

A la següent escena, quan aquest pastor expliqui als seus companys el somni inspirador i les veus que va escoltar, farà referència als mateixos interlocutors invisibles: Febo i Talia, «un irat, altre quexosa» els han escollits a ells «per los primers catalans, / que a noble teatro dónan / las flors cultas del Pernàs» (vv. 251 i 260-262). Guidèmio comminarà a acceptar el repte que li ha estat cantat en somnis a Fontano, perquè no hi ha res a témer «Tenint de Febo y Talia / lo patrosini sagrat» (vv. 303-304).

Són tantes les possibilitats musicals de la Tragicomèdia i tants els possibles actors i actrius amb habilitats suficients per interpretar cançons o executar recitatius, que no seria agosarat posar sobre la taula la hipòtesi que la gran majoria d'aquesta festa teatral podria ser musicada, atès que fins $i$ tot el graciós Posimico, encara que desafini i canti burlescament «llo fret me torna ronch, / la gargamella se arruga / y se m gela lo cañó» (vv. 1452-1454)-, s'atreveix a interpretar diverses cançons o, més aviat a «buydar un altre to» «al anbut de sas orelles» (vv. 1433-1434).

\section{Conclusions}

En aquestes línies s'ha volgut demostrar que els mèrits metateatrals de la Lloa per la Tragicomèdia pastoral d'amor, firmesa i porfia els aconsegueix Francesc Fontanella gràcies a l'experimentació amb la música i la poesia, arts agermanades en la seva dramatúrgia i de les quals explota les possibilitats escèniques amb una sensibilitat plenament barroca. Ens trobem doncs a les antípodes des que Magí Pers i Ramona edità la Tragicomèdia l'any 1863 suprimint-ne la Lloa degut a no considerar-la suficientment interessant o fins i tot grollera (Miró 1988: 22). És coherent pensar que la innovació de recursos expressius per part del poeta barceloní només podia desenvolupar-se en un context cortesà i per a un grup reduït o «noble auditori», segons es diu a la clausura de la peça breu (v. 371), la qual cosa, juntament amb característiques formals i de contingut de la lloa, ens duria a classificar-la com a cortesana en sentit ampli, és a dir, no només per a representar-se en un palau oficial davant la reialesa, sinó també en una casa noble particular davant personalitats distingides de l'elit local.

Hem anomenat aquesta peça anti-lloa en tant que es nega a si mateixa i, paradoxalment és negantse que existeix. I no només es nega com a tal, afirmant-ne els personatges que no existeix el gènere en què es troben, sinó que també, en un virtuosisme estructural i metaliterari, el personatge sobrenatural de la Música anul la l'anti-lloa que estaven representant per proposar un futur argument per a la Tragicomèdia, per la qual cosa, la no-lloa queda doblement negada. S'han presentat uns quadres analítics vinculant forma mètrica, mode d'expressió i continguts, dels què s'han extret claus poeticomusicals de tota la lloa amb l'accent a la segona escena, vertader clímax metateatral de la peça. En aquesta, Fontanella aconsegueix un gran espectacle audiovisual, sincronitzant perfectament música, vers i imatge, com es pot veure en l’acotació «Mentres se canta la lletra se alsarà una cortina y se descubrirà Fontano assentat, ab una lira a la mà, y en la altra una corona de flors, y mentras se canta

SCRIPTA, Revista internacional de literatura i cultura medieval i moderna, núm. 11/juny 2018/pp. 178-199 ISSN: 2340 - 4841 doi:10.7203/SCRIPTA.11.12592 
Gaston Gilabert. L’èxtasi poètic de Fontanella: metateatre i música a la Lloa per la Tragicomèdia pastoral d'amor, firmesa i porfia

la última quarteta ix al teatro» (v. 160 acot.), on observem la ficcionalització de la figura del poeta barceloní revestit amb atributs apol linis, disposat a harmonitzar artísticament i elevar diferents ingredients vinculats a allò baix o popular. Amb el començament totalment còmic de la lloa i amb el posterior clímax de l'al legoria de la inspiració, sembla com si Fontanella volgués mostrar als espectadors el procés pel qual un escultor de la paraula poètica desbasta la pedra bruta per extreure'n de dins l'obra d'art. La plasmació en pàgines de l'èxtasi que va tenir Santa Teresa es podria posar al costat d'aquesta escenificació de l'«èxtasi de poeta» a la Lloa.

Per la seva particularitat en tant que personatge, ha estat necessària una reflexió sobre la identitat que amaga el locutor «Música» i així poder veure que sovint oculta conjunts de música instrumental i de música vocal. Tanmateix, s'han analitzat altres personatges tot proposant una nova interpretació que els faria més propicis al cant o al recitatiu que al declamat d’una comèdia estàndard, especialment en determinats passatges.

En definitiva, la Lloa fontanellana és una demostració virtuosisme barroc en un brevíssim espai de temps. En treballs posteriors caldria posar en relació els elements metateatrals i poeticomusicals que han anat sortint a la llum amb la resta de peces dramàtiques de la pròpia Tragicomèdia $\mathrm{i}$ amb la resta d'obres poètiques i teatrals de Fontanella, ja que un artista amb unes preocupacions estètiques tan extremades rarament produeix una realització aillada, sinó que les desplega en vasos comunicants a través de tota la seva trajectòria literària. 
Gaston Gilabert. L’èxtasi poètic de Fontanella: metateatre i música a la Lloa per la Tragicomèdia pastoral d'amor, firmesa i porfia

\section{Bibliografia}

Antonucci, F. (2000) «Más sobre la segmentación del texto teatral: el caso de Peribáñeay el Comendador de Ocaña), Anuario Lope de Vega, 6, pp. 19-377. (2010) «La segmentación métrica, estado actual de la cuestión», Teatro de palabras, 4, pp. 77-

Aznar, D. (2014) «La Revolución del Siglo’ (1644): Una mise en abyme teatral de la unión de Cataluña y Francia en la corte virreinal de Barcelona», 7 Mares. Revista dos ós-graduandos em história moderna da Universidade Federal Fluminense, 5, pp. 72-84.

Brown, K. (1987) «Context i text del Vexamen d'acadèmia de Francesc Fontanella», Llengua \& Literatura, 2, pp. 173-252.

Cotarelo y Mori, E. (2000) Colección de entremeses, loas, bailes, jácaras y mojigangas desde fines de siglo XVI a mediados del XVIII (2 vols.), Granada, Universidad de Granada.

Fontanella, F. (1988) Tragicomèdia pastoral d'amor, firmesa i porfia. Lo desengany, poema dramàtic, ed. M. M. Miró, Barcelona, Institut del Teatre.

Genette, G. (1987) Semils, Paris, Seuil.

Gilabert, G. (2015A) L'esperit del llibre, Barcelona, Rema 12.

—. (2015B) «La teoría de la segmentación métrica frente a las secuencias poético-musicales en el teatro del Siglo de Oro», Vozy Letra, XXVI/2, pp. 75-83.

—. (2017A) «"I will play the swan and die in music”. Shakespeare y Lope de Vega ante la música teatral trágica», Anuario Lope de Vega. Texto, literatura, cultura, XXIII, pp. 270-285.

—. (2017B) Música y poesía en las comedias de Bances Candamo, Vigo, Academia del Hispanismo.

Josa, L. / Lambea, M. (2000) Libro de Tonos Humanos (1655-1656), vol. I, Barcelona, CSIC.

—. (2003) Libro de Tonos Humanos (1655-1656), vol. II, Madrid / Barcelona, CSIC.

- (2005) Libro de Tonos Humanos (1655-1656), vol. III, Madrid, CSIC.

- (2010), Libro de Tonos Humanos (1655-1656), vol. IV, Madrid, CSIC.

Miquel, F. A. (1967) Viatge a Catalunya d'un conseller del rei de França l'any 1603, Barcelona, Rafael Dalmau.

Miró, M. M. (1988) «Introducció», dins Fontanella, F. Tragicomèdia pastoral d'amor, firmesa i porfia. Lo desengany, poema dramàtic, ed. M. M. Miró, Barcelona, Institut del Teatre, pp. 11-50.

Rico, F. (1981) «Introducción», dins Vega, L. de El Caballero de Olmedo, ed. F. Rico, Madrid, Cátedra.

Rossich, A. (2001) «El teatre Barroc (segle XVII), dins Rossich, A. / Serrà, A. / Prats, D. (eds.) El teatre català dels origens al segle XVIII, Kassel, Reichenberger.

Rossich, A. / Valsalobre P. (2011) Literatura catalana moderna (siglos XVI-XVIII), Madrid, Síntesis. 
Gaston Gilabert. L’èxtasi poètic de Fontanella: metateatre i música a la Lloa per la Tragicomèdia pastoral d'amor, firmesa i porfia

Rubió, J. (1985) Historia de la literatura catalana, vol. II, Barcelona, Publicacions de l'Abadia de Montserrat.

Solervicens, J. (dir.) (2017) Història de la literatura catalana, vol. IV, Barcelona, Enciclopèdia Catalana / Barcino.

Spang, K. (1994) «Aproximación a la loa sacramental y palaciega: notas estructurales» dins Arellano, I. / Spang, K. / Pinillos, M. C. (eds.) Apuntes sobre la loa sacramental y cortesana. Loas completas de Bances Candamo, Kassel, Reichenberger, pp. 7-24.

Tegell, F. (1989) Poema anaforic, ed. K. Brown, Barcelona, Publicacions de l'Abadia de Montserrat.

Torrent, A. M. (1984) «Poesia barroca de la Guerra dels Segadors», Els Marges, 31, pp. 81-100.

Vitse, M. (1998) «Polimetría y estructuras dramáticas en la comedia de corral del siglo XVII: el ejemplo de El Burlador de Sevilla», dins Campbell, Y. (ed.) El escritory la escena, VI: Estudios sobre teatro español y novohispano de los Siglos de Oro, Ciudad Juárez, Universidad Autónoma de Ciudad Juárez, pp. 45-63. 